\title{
MATERIAL SELECTION FOR A NEW TYPE OF FIRE EXTINGUISHER
}

\author{
L. Lambert ${ }^{1}$, W. De Waele ${ }^{1}$, G. Van De Vijver ${ }^{2}$ \\ ${ }^{1}$ Ghent University, Laboratory Soete, Belgium \\ ${ }^{2}$ Optimize Services, Belgium
}

\begin{abstract}
Nowadays safety is a hot topic, damage inflicted to human beings is intolerable. Fire safety is a big concern in industrial areas, but in residential areas a lot less precautions are in place. Therefore a new type of fire extinguisher should be developed that should encourage the installation of fire extinguishers in commercial environments and at home. The design of this fire extinguisher has to answer to a lot of demands. From a legal point of view, the extinguisher has to comply with the PED regulations and the EN 3 standard. Extra demands are, given the purpose, superb performance, great ergonomics and an attractive visual design.
\end{abstract}

One of the steps in the design process is to make a material selection based on needed and desired properties of materials. Also the possible processes for manufacturing are an important parameter.

Keywords performance index, EN3, PED, materials selection

\section{INTRODUCTION}

In modern Western society, safety is one of the utmost important issues. Regulations to ensure safety of people and environment are omnipresent. One of the dangers human beings are rather frequently confronted with, is fire. As a result, a lot of safety measures have been developed over the ages. With current fire extinguishers, fires of different natures can be extinguished with a high efficiency, if the size of the fire is not too big.

In industrial environments, regulation dictates a very strict fire prevention policy. In residential areas, however, a lot less precautions are in place. The only safety measures are the conceptual and structural design of the buildings. Although a large percentage of the fires people are confronted with occur at home, most people do not have any fire extinguishing equipment at home. A lot of fires that result in destroying one's belongings and cause a lot of casualties, can be easily controlled, even without training, if a proper extinguisher or fire blanket is present and the fire is noticed in an early stage. Also in commercial environments, (restaurants, stores,...) fire extinguishers are placed out of sight for esthetical and practical reasons.

In order to encourage private consumers to install fire extinguishers at home, developing a new type of fire extinguisher might be a decisive factor. This type has to be highly functional, ergonomic and esthetic. This should lower the threshold for people to place a fire extinguisher in their homes, especially if people are made aware that this greatly reduces the risk of immense fire damage. An attractive design might also encourage restaurants and stores to put fire extinguishers in easily accessible and visible locations to increase safety. Some manufacturers have already developed designer extinguishers, but at the cost of a serious decrease in performance compared to the types developed with focus on performance.

European and national legislation dictates that portable fire extinguishers have to comply with both the pressure equipment directive (PED)[1] and the EN 3 standard [2]. These include an entity of empiric design rules and a series of tests the extinguisher has to pass. Furthermore they limit the types of materials that are allowed for the construction of the portable fire extinguisher. These prescriptions will be limiting factors at several levels of the design.

Improvement of current designs is possible on several aspects. In this study, the most prominent aspect will be using carefully selected materials in an optimized configuration. This might allow the construction of a (super-)lightweight extinguisher, with superior performance, as discussed below. Optimal materials selection and usage might as well make more daring designs possible.

Another important and related challenge will be selecting the most suited manufacturing and assembly processes to produce the device. A critical study has to be performed of the currently used techniques at the production site. 
Also the ecologic impact of the design will be taken into account, (recyclability, impact of production on environment,... ).

\section{CURRENT SITUATION}

A typical modern fire extinguisher, (Fig. 1) consists of a steel, (e.g. ST12) cylindrical hull, with a typical thickness of about 1,5 to $2 \mathrm{~mm}$. On the inside of the hull, usually a coating, (epoxy, polyester) is fitted to protect it from corrosion. On the outside, the hull is protected by a layer of paint.

For the production of the hull, a series of processes are used. Starting from steel coils, the two main parts of the hull are deep drawn. Afterwards, these two parts are welded together and the filling opening is cut out and finished by welding in a top part with thread. A metallic tap (brass or chrome), is screwed on. The hose is made of flexible rubber and the nozzle is usually a type of plastic.

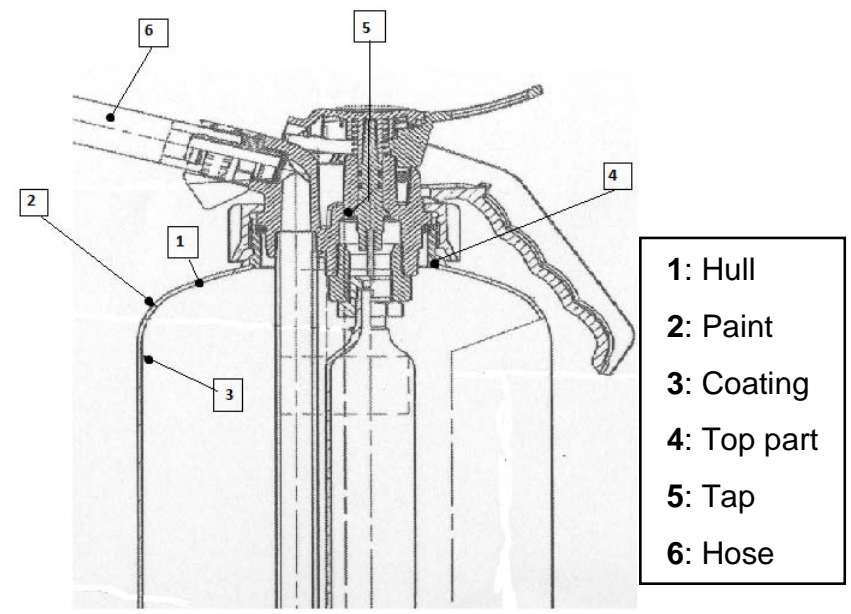

Fig. 1 Schematic current design

There are almost no types that deviate from a cylindrical hull form. This form is very robust and is easily constructible.

Based on the fire extinguishing agent, three types of fire extinguishers can be distinguished: $\mathrm{CO}_{2}$ powder or foam extinguishers. Based on capacity, typical extinguishers contain 3, 6 or 9 litres, (foam) or 3, 6 or 9 $\mathrm{kg}$, (powder). Concerning pressure a distinction can be made between types with stored pressure and with a pressure cartridge.

Considering the purpose or this fire extinguisher, a foam extinguisher with a capacity of 6 litres is the most suiting of these types. In order to simplify efficient inspection, a pressure cartridge is recommendable.

\section{BOUNDARY CONDITIONS: DEMANDS \& DESIRED PROPERTIES}

\subsection{Legislation : EN3 \& PED}

The design of portable fire extinguishers has to comply with European legislation: PED and EN 3 (sections $7 \&$ 8). EN 3 is a European harmonized standard consisting of 10 parts and specifically developed for portable fire extinguishers. PED is a general European directive for pressurized equipment and translated into national legislation [3]. A portable fire extinguisher cannot be placed on the European market before its conformity with legislation has been evaluated by a notified body. In Belgium this is done by ANPI or APRAGAZ.

PED and EN 3 include lists of empirical rules to make sure that any design matching these criteria can be considered a safe device with a required performance level. For the basic design, some important limitations are:

1) Allowed materials

2) Max. weight

3) Min. hull thickness + permissible stress
4) Corrosion resistance

5) Electrical conductivity

6) Mechanical integrity (crushing, impact, ...) 
Some other basic limitations are practical demands to ensure that easy and safe handling is always guaranteed. With regard to the design aspects discussed in subsequent paragraphs,1), 2) and 3) are considered to be the most relevant qualifications. The weight of a portable fire extinguisher is not allowed to exceed $20 \mathrm{~kg}$ and a lower weight is always advantageous. The selection of materials according to these criteria will be discussed in section 4 .

The minimum hull thickness for portable fire extinguishers with a metallic body, depends on the chosen alloy and is dictated by the standard EN 3 (part 8). For austenitic steel alloys, the minimum thickness (s) is given by equation (6). For all other alloys, the minimum thickness is calculated with equation (7).

$$
\begin{aligned}
& \mathrm{s}=\frac{\mathrm{D}}{600}+0,3[\mathrm{~mm}] \\
& \mathrm{s}=\frac{\mathrm{D}}{\mathrm{a} 00}+\mathrm{K}[\mathrm{mm}]
\end{aligned}
$$

where $D$ is the diameter of the hull and $K$ varies from $0,45 \mathrm{~mm}$ up to $0,7 \mathrm{~mm}$, depending on $D$.

In PED and EN 3, also a series of tests are specified, to which the device has to be submitted. These consist of a crash test, a corrosion test, a creep test, a fatigue test, a pressure test and a burst test.This last test has to guarantee the structural integrity in case of failure. This implies that the failure behaviour of the material may not be characterized by brittle crack. Hence, ductility will be an important parameter of the material selection process. The described pressure test has to be performed at a pressure $p \geq 1,43 . P S$, where PS is the maximum allowable pressure in the vessel.

\subsection{Desired properties}

Apart from the demands due to legislation, several material characteristics will be desirable from the viewpoint of the producer and his customers. First of all, the designer or user will favour low weight, low cost, good formability and ductility,...

On the other hand, society in general will be concerned with sustainability and the impact on the environment. In this respect, the recyclability of the materials, the energy cost related to the production of the device, $\mathrm{CO}_{2}$-exhaust caused by construction and the availability of the selected materials (rare resources) will be important factors. Even the amount of water needed for the production can be used as a criterion. These "environmental costs" should be reduced as much as reasonably possible.

Several degrees of sustainability can be considered. For some materials recycling simply is not an option (e.g. some composites can only be broken down by combustion). For other materials, a distinction will be made between cradle to grave recyclability, where the material is degraded every time it is recycled, and cradle to cradle recyclability [4] where materials can be recycled without degrading. Steel alloys often allow cradle to cradle recycling, which gives them an inherent advantage compared to other materials.

The challenge is to design the device as such, that it complies with both regulations and satisfies as much of the previously mentioned desirable characteristics as possible.

A systematic method to select materials with the desired properties is discussed in section 4 .

\section{MATERIALS SELECTION}

\subsection{Procedure}

A very effective way to visualize the feasibility of different material types for a certain application, is using so-called 'Materials Selection Charts'. This graphical method was developed by M.F. Ashby and D. Cebon [3]. For a series of materials, a certain material characteristic is displayed in function of a second characteristic. In that way, different zones can be distinguished corresponding to more or less preferable combinations of properties. Examples of meaningful properties were discussed in section 3.2. If a series of charts are compared, one can make an evidence-based selection of the materials to be used.

More often however, a combination of several (sometimes conflicting) properties will be advantageous. In this case it will be difficult to get a conclusive result with Materials Selection Charts. Performance indices [3] allow to quantify the aptitude of materials for certain applications. Depending on the properties that are considered to be most significant, different performance indices can be specified. These indices are obtained by combining certain properties like density, yield strength, cost, ... Like this, materials can be 
sorted based on increasing or decreasing values of a performance index. Extreme values of performance indices will be associated with very advantageous or disadvantageous combinations of properties.

For the application of a fire extinguisher, different performance indices can be defined. As an illustration, three completely different indices (related to construction, cost and durability) will be discussed in subsequent paragraphs.

\subsubsection{Weight}

The weight of the hull is an important parameter from the viewpoint of both legislation and customer requirements. For a certain hull geometry with a specified thickness, one can calculate the stresses $\left(\sigma_{\mathrm{rr}}\right.$ in radial direction and $\sigma_{\theta \theta}$ in circumferential direction) in the hull. For a cylindrical hull for example, this can easily be calculated based on the formulas of Lamé [2],

$$
\begin{aligned}
& \sigma_{r v}=p \frac{a^{2}}{a^{2}-b^{2}}\left(1-\frac{b^{2}}{r^{2}}\right) \\
& \sigma_{\theta \theta}=p \frac{a^{2}}{a^{2}-b^{2}}\left(1+\frac{b^{2}}{r^{2}}\right)
\end{aligned}
$$

Where $a$ and $b$ are the inner and outer radius of the cylinder hull and $r$ the radius at which the stress is calculated.

The stress $\sigma_{\mathrm{zz}}$, as displayed in Fig. 1, is calculated as: $\sigma_{z z}=\mathrm{p} \frac{\pi a^{2}}{\pi b^{2}-\pi a^{2}}$.

For a thin-walled vessel, these equations can be simplified as:

$$
\begin{aligned}
& \sigma_{\theta \theta}=\frac{p a}{t} \\
& \sigma_{z z}=\frac{p a}{2 t}
\end{aligned}
$$

Where $t$ is the hull thickness.

For more complicated geometries, it will be difficult to derive an analytical solution for these stresscomponents and finite element models may have to be used.

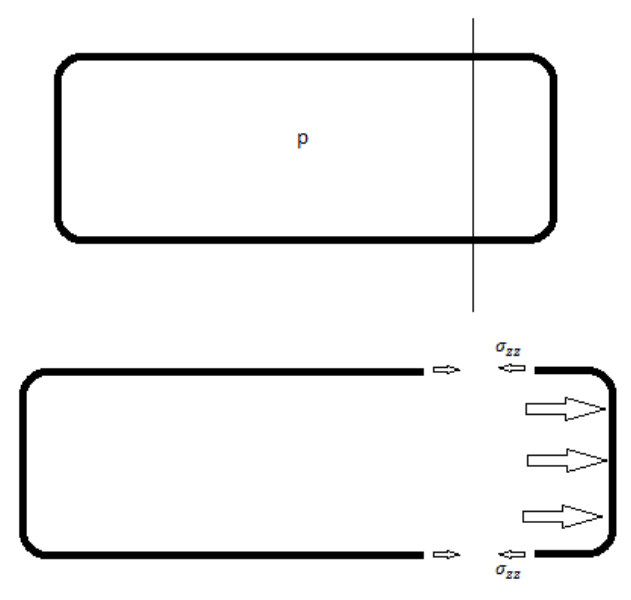

Fig. 2: Axial stress in the cylinder of a thin-walled pressure vessel.

Using the Von Mises yield criterion (for ductile materials), an equivalent stress can be calculated and compared with the material's yield strength. Taking into account a safety factor, this will allow to determine the minimum required wall thickness. Or, starting from a specified geometry of the hull, one can calculate the minimum required yield stress of the material.

The volume $V$ of material that is used determines the thickness $t$ of the hull. For thin-walled vessels, $V$ and $t$ are directly proportional and the stress in the hull is inversely proportional to $t$. As a result, there is an inversely proportional link between $V$ and the required yield stress $\sigma_{0}$.

In order to optimize the weight of the hull, this weight is written as a function of the volume $V$ and the density $\rho$ of the materials:

$$
W=V \cdot \rho=\frac{1}{C_{1} \sigma_{0}} \rho
$$


where $C_{1}$ is a constant and $\sigma_{0}$ the yield stress of the material. A first performance index $M_{1}$ can be defined as:

$$
M_{1}=\frac{\sigma}{\rho}
$$

Materials with a very high index $M_{1}$ will allow the lightest construction.

\subsubsection{Material cost}

The material cost of the hull will also be an important parameter. The total material cost $K$ of the hull is a function of the material cost per unit mass $k$, the density $\rho$ and the volume $V$ of materials used.

$$
K=V \rho k=\frac{1}{c_{1} \sigma} \rho k
$$

A second performance index $M_{2}$ can be defined as:

$$
M_{2}=\frac{\sigma}{\rho k}
$$

Materials with a higher $M_{2}$-index will possibly allow a cheaper hull. It has to be noted that the considered cost only consists of the material purchase cost. The cost of the processing operations is not taken into account and needs further consideration.

\subsubsection{Durability aspect of production}

Regarding production, several indices can be defined. The daily costs for producing the components could be brought into account, or even the required investment costs for starting up a new type of manufacturing processes.

In this paper the ecological aspects of the production are taken into account.

A third performance index $M_{3}$ is specified as:

$$
M_{a}=E_{p r o d} \cdot C_{C O 2} \cdot U_{w}
$$

Where $E_{\text {prod }}$ is the embodied energy for primary material production $[\mathrm{MJ} / \mathrm{kg}], C_{\mathrm{COO2}}$ represents the $\mathrm{CO}_{2^{-}}$ exhaust caused by the production process $[\mathrm{kg} / \mathrm{kg}]$ and $U_{w}$ is the water usage $[1 / \mathrm{kg}]$.

Unlike $M_{1}$ and $M_{2}$, low values of $M_{3}$ will be desirable. The production of materials with a low index $M_{3}$ will have a low impact on the environment.

\subsubsection{Other indices}

Several other performance indices could be specified based on cost considerations or mechanical integrity aspects (resistance to fatigue, corrosion and impact damage). These indices can be used to further eliminate materials, but are not further discussed in this paper.

Also selections can be made by rejecting materials that are (strongly) degraded by recycling, are not biodegradable or by specifying a lower limit for the fraction that is expected to be actually recycled.

\subsection{Implementation}

\subsubsection{Primal selection of material classes}

Before applying the above discussed methods, one can already determine which classes of materials will be worth considering, based on some of their general characteristics.

Applied to the case of a portable fire extinguisher, this results in the rejection of:

- Ceramics or glasses: since they are very brittle and sometimes porous.

- Magnetic materials: magnetic behaviour is an undesirable property.

- Materials that are not watertight (fibres, particulates, foams,...): the contents of the vessel may not be lost.

This primal selection already greatly reduces the amount of materials that should further be considered. In subsequent paragraphs, materials that didn't pass this first selection are therefore not taken into account. 
One can also reflect in advance what kind of materials might have advantageous characteristics for this application and can be expected to survive the following selection.

- Steel alloys might be well worth considering, since they typically have high yield strengths and are available at a relatively low cost.

- Composites might be advantageous, since they have high tensile strengths and low densities.

- Some other metal alloys (Al, Mg, Ti...) might be worth considering, since they have high yield strengths and lower densities than steel.

However, selection of the most feasible material(s) should be based on a systematic and evidencebased approach as described in section 4.1.

\subsubsection{Further selection based on materials selection charts and performance indices}

In order to come to a profound selection, all needed and desired properties of the materials have to be listed and critically compared.

Software packages, like CES-Edupack [5] have extensive libraries of materials and their properties. This software package is used to develop graphs of the previously discussed parameters. As an illustration, a Materials Selection Chart can be made where yield strength is displayed in function of the material cost per volume. This graph (Fig. 3) is useful to get a clear view on the material costs that can be expected for certain material classes. The straight lines with slope $=1$ are constant material cost-lines. The difference between two subsequent lines is a factor 10. It is clear that the group of 'Gold, Platinum and Palladium alloys' and the group of 'Tungsten, Tantalum and Zyrconium alloys' will be to expensive for this case. Elastomers and plastics are beneficial from the viewpoint of cost, but have too low strength properties. This graph also shows that the family of steel alloys are, in terms of strength and cost, very advantageous materials.

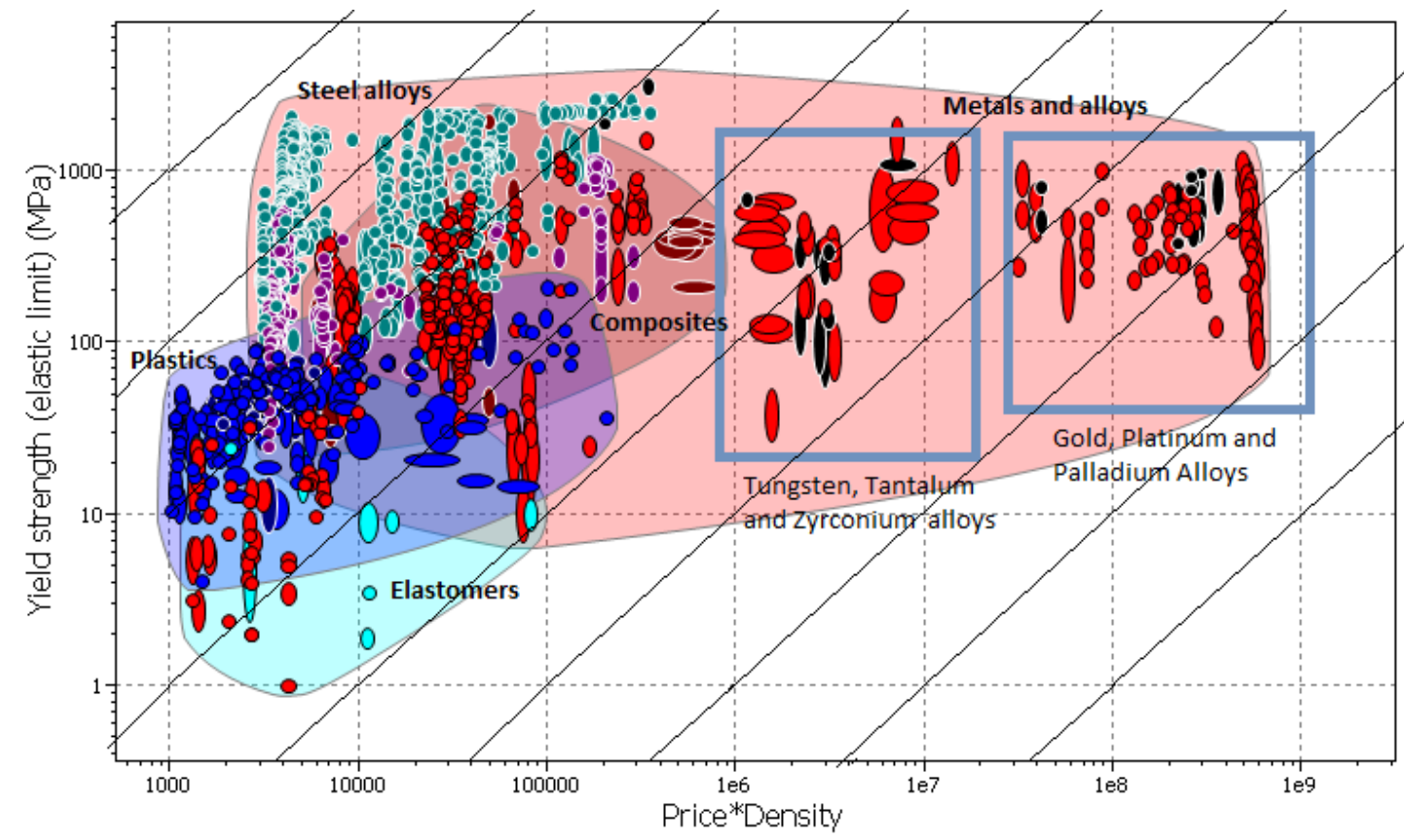

Fig. 3 Materials Selection Chart: evaluation of strength and cost

If performance index $M_{1}$ is calculated for the selected materials (section 4.2.1), values ranging from $5^{\star} 10^{-4}$ $\mathrm{kN} . \mathrm{m} / \mathrm{g}$ up to $1,5 \mathrm{kN} . \mathrm{m} / \mathrm{g}$ are found. As a first selection criterion, a lower limit of $0,1 \mathrm{kN} . \mathrm{m} / \mathrm{g}$ is specified for $M_{1}$. The fact that a minimal thickness is required due to legislation is not taken into account. This may reduce the advantage of using materials with extreme high values of performance index $M_{1}$.

In a similar way performance index $M_{2}$ can be calculated. This parameter varies from $5^{\star} 10^{-8} \mathrm{kN}$. $\mathrm{km} / €$ up to $0,5 \mathrm{kN} . \mathrm{km} / €$. A lower limit for $M_{2}$ is specified at $10^{-2} \mathrm{kN} \cdot \mathrm{km} / €$.

Performance index $M_{3}$ varies from $200 \mathrm{~L} . \mathrm{J} / \mathrm{g}^{2}$ up to $10^{15} \mathrm{~L} . \mathrm{J} / \mathrm{g}^{2}$. For this index, an upper limit is specified at $10^{5}$ L.J $/ \mathrm{g}^{2}$. 
The defined limits will greatly reduce the number of materials that should be considered. For this selection, $M_{1}, M_{2}$ and $M_{3}$ are displayed respectively in Fig. 4, Fig. 5 and 6. A logarithmic scale is used to get a wellinterpretable graph for a very wide range of materials.

It can be noted that $M_{3}$ (related to the durability of the production processes) filters out almost all materials except steel alloys. Dozens of steel alloys are selected, while the only other materials that survive the selection are glass fibre reinforced epoxies (composite material).

Most of the steel grades that are selected are tool steel alloys, low alloy steels and carbon steels.

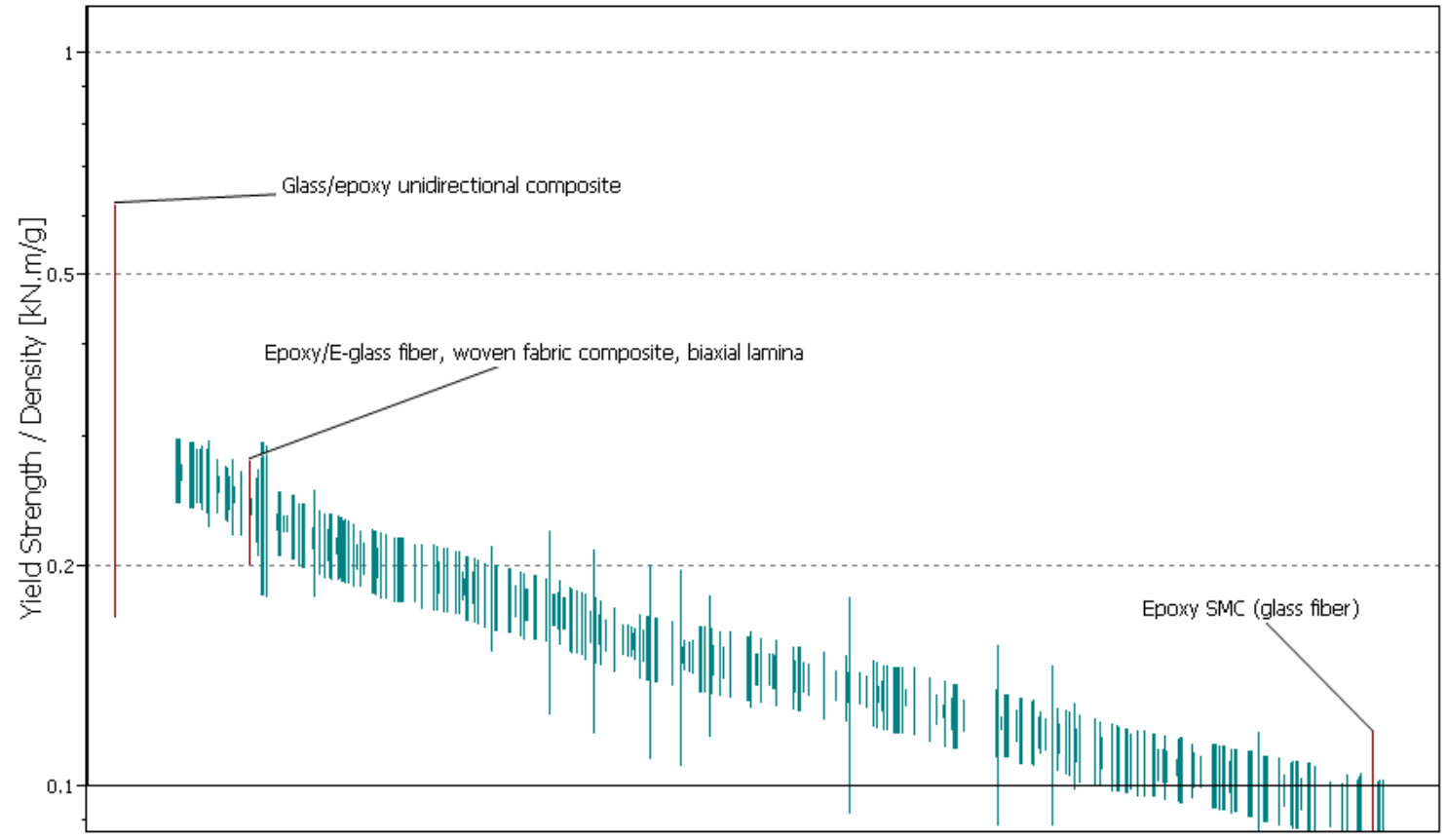

Fig. 4 Performance index $\mathrm{M}_{1}$

The best result regarding low weight (index $M_{1}$ ) is achieved with a glass/epoxy unidirectional composite, which is amongst others used in hulls of ships. For the selected steel alloys, no consistent trend can be established concerning performance for $M_{1}$.

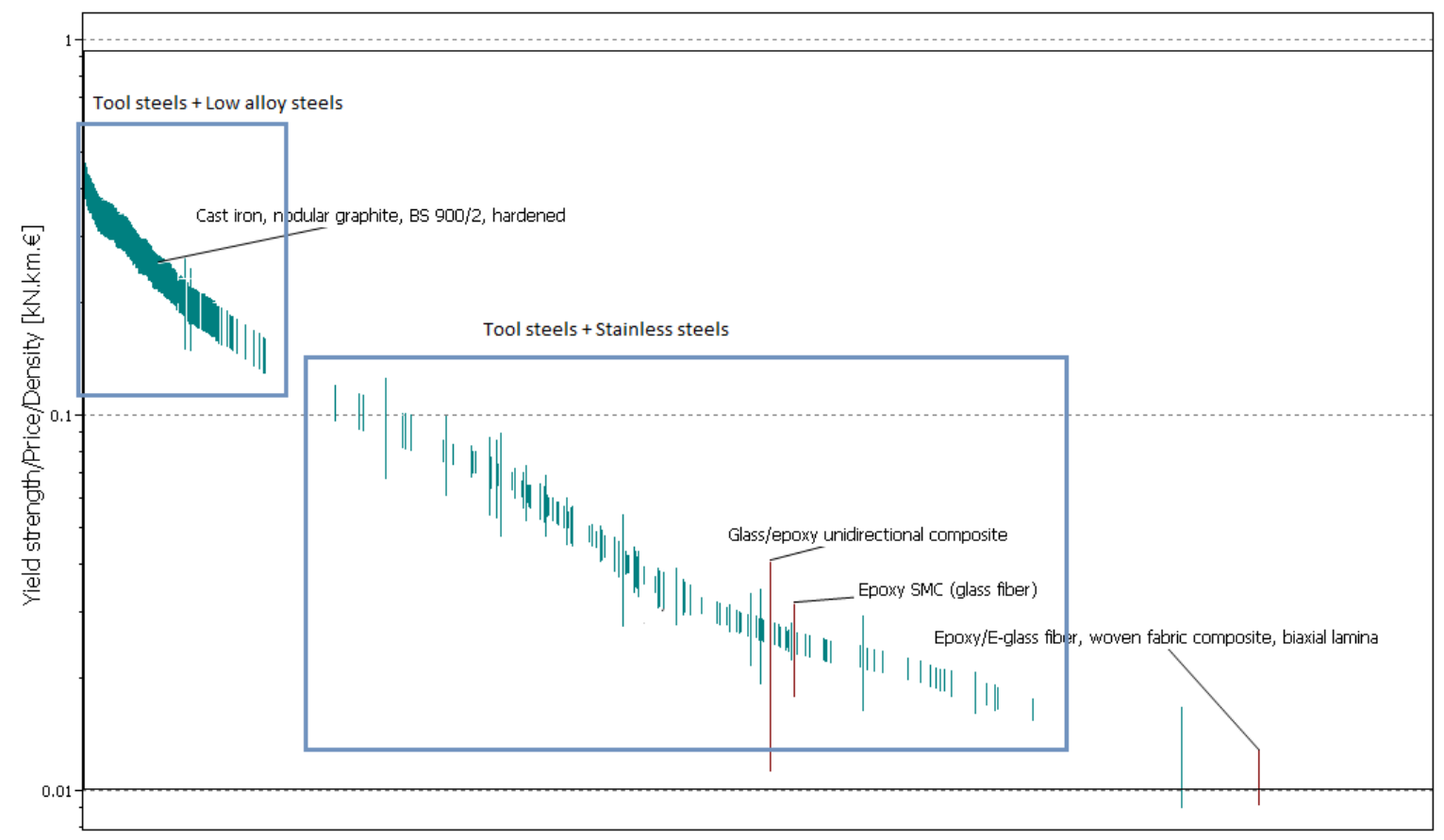

Fig. 5 Performance index $M_{2}$ 
With respect to material cost (index $\mathrm{M}_{2}$ ), steel alloys give the best result, and the selected composites are situated closer to the defined lower limit. It should also be noted that the steel alloys with better results for $M_{1}$ tend to have a worse $M_{2}$-value and vice versa.

This situation could be expected from the start and illustrates the compromise that has to be made.

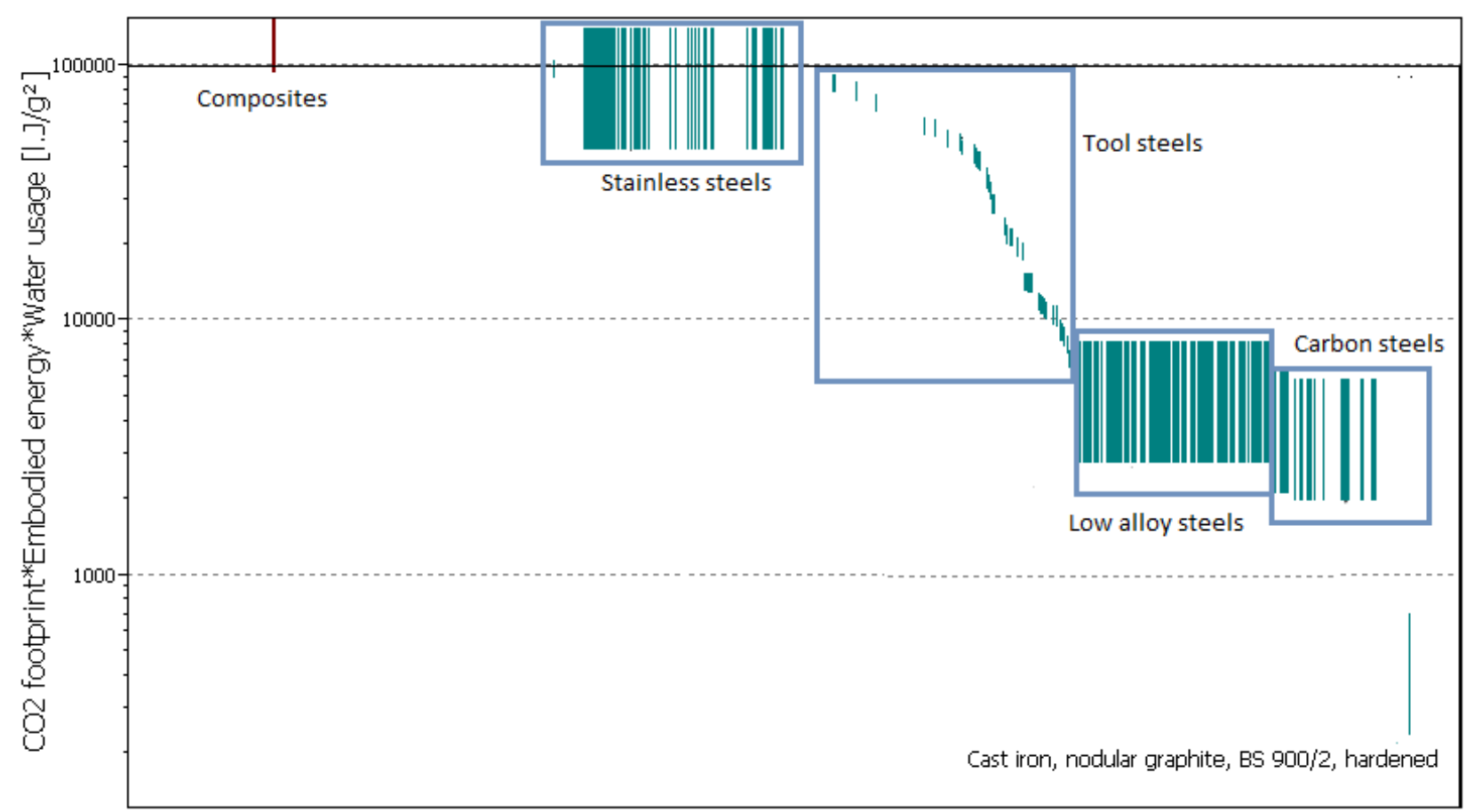

Fig. 6: Performance index $\mathrm{M}_{a}$

With regard to durability of production (index $M_{3}$ ), low alloy steels and carbon steels obviously show very good results (Fig. 6). The best result is achieved for a hardened cast iron (nodular graphite, BS 900/2).

When all performance indices are taken into account, the family of low alloy steels appear to be very attractive materials for portable fire extinguishers. Based on the discussed evaluation procedure, the material with the most attractive properties is a low alloy steel, type AISI 9255 (tempered at $205^{\circ} \mathrm{C}$ and oil quenched)This steel alloy has a yield strength of $1840 \mathrm{MPa}$. For this material $M_{1}=0,3 \mathrm{kN} \cdot \mathrm{m} / \mathrm{g}$, $M_{2}=0,5 \mathrm{kN} . \mathrm{km} / €$ and $M_{3}$ ranges from 500 up to $900 \mathrm{I} . \mathrm{J} / \mathrm{g}^{2}$. By redefining the upper and lower limits for the performance indices, different results can be obtained.

Only when the weight of the hull is the decisive factor, composites will be considerable. The nonrecyclability of most composites is however a great disadvantage that has not yet been taken into account and might exclude composites altogether.

\subsection{Low alloy steels}

Since low alloy steels seem to be very promising materials for this application, it is useful to take a closer look at this group of materials. Depending on the techniques used to produce the steel and the composition of the alloy, a huge variety of steels can be obtained. Although steel alloys have been the most important engineering materials since about 1800 , still a lot of research is performed to develop new steel grades. The microstructures that occur in the steel alloy, (ferrite, martensite, bainite, pearlite, austenite), will determine its properties, such as yield strength, ductility,...

Of course, not all low alloy steels are included in the CES libraries. Some recently developed grades that are worth considering are the Advanced High Strength Steels ( AHSS) [8]. These include dual phase steels (DPS), transformation induced phase (TRIP) steels and complex phase steels. All these grades have very advantageous mechanical properties (high strength and good ductility) and wide processing possibilities. For this kind of application, DPS seem to be well suited [9],[10],[11]. These steel grades typically have a 
fine ferrite structure with a second harder phase as strengthener. They are also suitable for deep drawing and other processing techniques (cf.5.2), which makes them very attractive in this context.

AHSS as described by Z. Xiaodong [8] have yield strengths ranging from $400 \mathrm{MPa}$ up to $1400 \mathrm{MPa}$, depending (DPS, CPS and TRIP). These steels will not necessarily obtain the highest values for $M_{1}$ and/or $M_{2}$, but the advantage in processing abilities might be significant. Also a very good strength-ductility combination is obtained with these steel grades [8]. It has to be noted that the previously defined performance indices are merely an illustration of the possible indices that can be used for the selection process. In order to make a more profound selection, an extensive set of indices has to be evaluated.

As noted in section 4.2.2 the advantage of high $M_{1}$ indices will be limited by the minimal thickness required by legislation.

Also the availability of the desired steel grade and the production form (coils,...) is an important issue that should be considered. For DPS, a number of standardized grades are available on a large scale in coils.

\section{PROCESSING}

\subsection{Composites}

For composites, the material is immediately produced into the desired component shape.

No forming processes have to be or can be performed afterwards. This has the advantage that almost every shape is possible, and that the material properties can't be deteriorated by the forming process.

On the other hand, a fire extinguisher is not supposed to have an exceptionally complicated form.

The anisotropic behaviour of these materials is a challenge that requires special attention and complicates the design. A lot of composites, like the previously mentioned glass/epoxy types however certainly are a possibility.

The production processes for composites are less suitable for mass production, and in general require more time. Composite pressure vessels are typically constructed with a filament winding on a permanent mould, which is used as an impervious coating for fluids.

\subsection{Steel}

Steel grades are typically produced in flat sheets and need subsequent forming steps to realize the desired shape. A possibility to avoid secondary forming processes, would be to use casting techniques. For this application however, this will not be advantageous in any way. Casting techniques are in general rather complicated and time consuming. In addition they are certainly not the most evident processes for creating hollow geometries. As a result, cast iron that was mentioned in earlier paragraphs will not be a valuable option.

Starting from a steel plate, a form can be created in several ways: deep drawing, bending, welding, hydroforming,... The feasibility of each of these techniques depends on the specific properties of each steel grade. The strength properties of the processed material will be a lot higher than those of the non-deformed steel due to strain hardening. For a fire extinguisher, the most obvious procedure is to create two shaped parts with deep drawing or hydroforming techniques and join them with a weld in the circumferential direction of the vessel. With hydroforming techniques, some hull geometries can be constructed in one part, which would save a lot of time, although this will reduce the possible geometries.

It is in this prospect that dual phase steels stand out [4], as mentioned in section 4.3. Both hydroforming and deep drawing allow a great variety of shapes, (single and double curved), which ought to be more than enough for any reasonable design of a fire extinguisher. Hydroforming has an extra advantage that it is possible to start from a tube-shaped part, which will need to be deformed less than a part that is constructed from a sheet. These materials are also capable of absorbing high amounts of energy, which can be useful with respect to the earlier mentioned impact tests.

The processing costs for steel will also be lower for steels than for composites, but a high installation cost will be unavoidable. 


\section{CONCLUSIONS}

The development of a new type of fire extinguisher can reduce the risks of fire damage in residential and commercial areas. The design has to comply with regulations and standards (PED and EN3). Further it has to unite several desirable properties, some imposed by society and others desired from a technical point of view. A selection procedure is established by using materials selection charts and performance indices. Three performance indices quantifying the performance of materials regarding weight, cost and impact of the production on the environment have been defined and evaluated. If weight is the decisive factor, glass/epoxy-composites are beneficial, but when other aspects are taken into account, low alloy steels are the materials with the best suited properties. Also when processing possibilities and recyclability are taken into account, steel grades turn out to be very advantageous materials. Dual phase steels are a modern class of low alloy steels with some very attractive properties for this specific application. This will be studied in more detail in the further progress of this work.

\section{NOMENCLATURE}

$\begin{array}{lll}a & \text { Internal Diameter Cylinder } & \mathrm{mm} \\ b & \text { External Diameter Cylinder } & \mathrm{mm} \\ \sigma & \text { Yield Strength } & \mathrm{MPa} \\ \mathrm{W} & \text { Weight } & \mathrm{kg} \\ \mathrm{V} & \text { Volume } & \mathrm{m}^{3} \\ \rho & \text { Density } & \mathrm{kg} / \mathrm{m}^{3} \\ \mathrm{~K} & \text { Cost } & € \\ \mathrm{k} & \text { Cost/weight } & € / \mathrm{kg} \\ E_{\text {prod }} & \text { Embodied Energy for production } & \mathrm{MJ} / \mathrm{kg} \\ C_{\mathrm{Co2}} & \mathrm{CO}_{2} \text {-exhaust } & \mathrm{kg} / \mathrm{kg} \\ U_{w} & \text { Water usage } & \mathrm{I} / \mathrm{kg}\end{array}$

\section{REFERENCES}

[1] Directive 97/23/EC of the European Parliament and of the council of 29 May 1997 on the approximation of the laws of the Member States concerning pressure equipment, 2003.

[2] EN3, Portable fire Extinguishers, 2007.

[3] Belgisch Staatsblad, 38063-38123, 8-10-1999.

[4] McDonough, W., Braungart, M., Cradle-to-cradle: Remaking the Way We Make Things, 2002.

[5] Ashby, M.F., Cebon, D., Materials Selection in Mechanical Design, Euromat, 1993.

[6] CES Edupack, Granta Design Limited, version 6.0.2.

[7] Van Paepegem, W., De Waele, W., Mechanica van Materialen, UGENT, 2010.

[8] Xiaodong, Z., Zhaohui, M., Li,W., Current Status of Advanced High Strength Steel for Auto-making and its Development in Baosteel,

[9] Vanrostenberghe, S, Goudemez, J., Chiappini, M., Brun, O., Desplaces, G., Bregnon,R., New Steel Grades For Light Weight LPG Cylinders.

[10] Schaeffler, D., Introduction to advanced high-strength steels- Part I, Stamping journal, 2005.

[11] Abedrabbo, N., Mayer, R., Thompson, A., Salisbury,C., Worswick, M., van Riemsdijk, I., Crash response of advanced high-strength steel tubes: Experimental and model, International Journal Of Impact Engineering, 36(8), 1044-1057, 2009. 